\title{
Curcumin inhibits tumor epithelial-mesenchymal transition by downregulating the Wnt signaling pathway and upregulating NKD2 expression in colon cancer cells
}

\author{
ZEWEI ZHANG ${ }^{1 *}$, HAITAO CHEN ${ }^{2 *}, \mathrm{CHAO} \mathrm{XU}^{3 *}, \mathrm{LU}^{*} \mathrm{SONG}^{2}, \mathrm{LULU} \mathrm{HUANG}^{3}, \mathrm{YUEBIAO} \mathrm{LAI}^{3}$, \\ YUQI WANG ${ }^{3}$, HANLU CHEN ${ }^{3}$, DANLIN GU $^{4}$, LILI REN $^{4}$ and QINGHUA YAO ${ }^{1,5}$ \\ ${ }^{1}$ Department of Abdominal Surgical Oncology, Zhejiang Cancer Hospital, Hangzhou, Zhejiang 310022; \\ ${ }^{2}$ Second Clinical College and ${ }^{3}$ First Clinical College of Zhejiang Chinese Medical University, Hangzhou, Zhejiang 310053; \\ ${ }^{4}$ Department of Integrated Traditional Chinese and Western Medicine, Zhejiang Cancer Hospital; ${ }^{5}$ Key Laboratory \\ of Traditional Chinese Medicine Oncology, Zhejiang Cancer Hospital, Hangzhou, Zhejiang 310022, P.R. China
}

Received November 16, 2015; Accepted March 10, 2016

DOI: $10.3892 /$ or.2016.4669

\begin{abstract}
Tumor invasion and metastasis are closely associated with epithelial-mesenchymal transition (EMT). EMT refers to epithelial cells under physiological and pathological conditions that are specific to mesenchymal transition. Curcumin inhibits EMT progression via Wnt signaling. The Wnt signaling pathway is a conservative EMT-related signaling pathway that is involved in the development of various tumors. In the present study, MTS assays were employed to analyze the proliferation of curcumin-treated cells. Naked cuticle homolog 2 (NKD2), chemokine receptor 4 (CXCR4) and antibodies associated with EMT were examined in SW620 colorectal cancer cell lines using western blot analysis and real-time qPCR. NKD2 small-interfering RNA (siRNA) and CXCR4 expression plasmid was synthesized and transfected into the colorectal cancer cell lines, and NKD2 and CXCR4 expression levels were detected. The results showed that curcumin significantly inhibited the proliferation of colorectal cancer cells and upregulated the expression of NKD2 in SW620 colorectal cancer cells and in the xenograft, resulting in the downregulation of key markers in the Wnt signaling. In addition, the progression of ETM was inhibited due to the overexpression of E-cadherin as well as the downregulation of vimentin. Curcumin also inhibited tumor metastasis by downregulating the expression of CXCR4 significantly. The results suggested involvement of the NKD2-Wnt-CXCR4 signaling pathway in colorectal
\end{abstract}

Correspondence to: Dr Qinghua Yao, Key Laboratory of Traditional Chinese Medicine Oncology, Zhejiang Cancer Hospital, 38 Banshan Road, Hangzhou, Zhejiang 310022, P.R. China

E-mail: yao_qh1@163.com

*Contributed equally

Key words: curcumin, naked cuticle homolog 2, Wnt signaling, chemokine receptor 4, epithelial-mesenchymal transition cancer cells. In addition, curcumin is inhibit this signaling and the development of colorectal cancer.

\section{Introduction}

Change to people's lifestyle and dietary habits have led to an increase in the incidence of colon cancer (1-3). Although there have been advances in the study of this type of cancer, colon cancer is a common gastrointestinal malignancy with a high mortality rate (4), owing to metastasis. Therefore, the main challenge is identification of methods to inhibit the metastasis of colon cancer effectively in the clinic. Metastasis occurs due to the interaction of multiple genes and is a complex system (5). However, the exact mechanism underlying metastasis of the disease remains to be elucidated.

Tumor invasion and metastasis are closely associated with epithelial-mesenchymal transition (EMT). EMT refers to epithelial cells under physiological and pathological conditions that are specific to mesenchymal transition (6). EMT has been associated with the initial stage of tumor metastasis, whereby tumor cells have lost the characteristics of epithelial cells and cell polarity, and attained the characteristics of mesothelial and invade adjacent tissues (7). This process is associated with change at the molecular level and the occurrence of cell morphology (8). In the evolution process of tumor growth, EMT includes alteration of cell polarity, reconstruction of the cytoskeleton, loss of intercellular adhesion and destruction of the tumor basement membrane and extracellular matrix between the cells (9), and mesenchymal phenotypes, such as high migration, invasion, resistance apoptosis and degradation of extracellular matrix. Therefore, EMT provides optimal conditions for invasion and metastasis, and tumor cell growth $(10,11)$. Previous findings showed that the EMT phenomenon is prevalent in tumor invasion and metastasis, such as in situ colon, breast, lung, and liver cancer, and plays an important role in tumor invasion and metastasis (12-14).

Chemokine receptor 4 (CXCR4) is a member of the superfamily of the seven-transmembrane G-protein coupled receptors 
and is the only receptor of CXCL12. CXCR4 is involved in a variety of physiological and pathological processes. The CXCL12/CXCR4 biological axis structure participates in the infiltration of inflammatory cells and lymphocytes, as well as migration and homing $(15,16)$. It also plays an important role in mediating tumor invasion and metastasis (17-20). Thus, CXCR4 is a common chemokine receptor in tumor cells, and its expression is increased significantly in gastric, lung, and breast cancer, as well as soft tissue sarcoma tumor cells.

In recent years, significant progress has been made in the study of the anti-tumor effects of traditional Chinese medicine, particularly with regard to natural plant-derived anticancer drugs that have become a global hot spot. Curcumin is a plant polyphenol that is extracted from the zingiberaceae plant, Curcuma longa root turmeric. Curcumin has various effects including antioxidant, anti-inflammatory, anti-atherosclerotic, and anti-aging, and also eliminates free radicals (21). Numerous studies have been conducted on the anti-tumor effects of curcumin and its mechanism worldwide. The findings have shown that curcumin obviously inhibits tumor invasion and metastasis in different tumor tissues $(22,23)$.

At present, some studies have reported that curcumin inhibits EMT in tumors (24). The Wnt signaling pathway is a conservative EMT-related signaling pathway that plays an important role in the development of a variety of tumors. The $\beta$-catenin is the hub of the molecule in the Wnt signaling pathway, which mediates the membrane and facilitates the transfer of molecules from the cytoplasm into the nucleus in the Wnt pathway $(25,26)$. Curcumin also reduced the level of $\beta$-catenin gene expression significantly; thus, it has anti-tumor effects through the inhibition of the Wnt signaling pathway $(18,27,28)$. Therefore, the mechanism of action of curcumin with regard to tumor inhibition remains to be determined. Using gene expression profiles, we analyzed the changes of tumor cell expression profiles of curcumin-treated cells, and identified inhibitors of the Wnt pathway naked cuticle homolog 2 (NKD2) (29). NKD2, as the Wnt signaling pathway regulation of gene suppression, significantly delayed the mitosis of HeLa cells (30). Thus, curcumin may inhibit the Wnt signaling pathway by regulation of the expression of NKD2. Previous findings showed that curcumin can also reduce the expression of CXCR4 in tumor cells $(31,32)$. Thus, according to the preliminary experiment, the mechanism of action of curcumin in colon cancer cells is likely to inhibit the Wnt signaling pathway by affecting NKD2 gene expression, EMT and the expression of CXCR4 in tumor cells and eventually inhibiting tumor invasion and metastasis.

\section{Materials and methods}

Reagents. Antibodies purchased for the present study included: axin and TCF4 (Cell Signaling Technology, Boston, MA, USA), $\beta$-catenin (Epitomics, San Francisco, CA, USA), NKD2 (Novus International, St. Charles, MO, USA), CXCR4 antibody (Thermo Fisher Scientific, Waltham, MA, USA), and $\beta$-actin (BD Biosciences, New York, NY, USA). Curcumin was purchased from Sigma (Beijing, China), and NKD2 small-interfering RNA (siRNA) from Shanghai GenePharma Co., Ltd. (Shanghai, China). The following two pairs of siRNA were designed: NKD2-homo-962 sense, 5'-CAGAUACAC AUGCCGUACATT-3' and antisense, 5'-UGUACGGCAU GUGUAUCUGTT-3'; NKD2-homo-480 sense, 5'-CACGCU CUAUGACUUUGACTT-3' and antisense, 5'-GUCAAAGUCA UAGAGCGUGTT-3'. NKD2 and CXCR4 primers were purchased from Biosune Biotechnology Co., Ltd. (Shanghai, China). NKD2 primers used were: 5'-ATGCCTCGGTCA ACCACTCC-3' and 5'-TCTGCCAGTTCACCCTCCATC-3' and the length of the product was $151 \mathrm{bp}$. CXCR4 primers used were: 5'-CCGTGGCAAACTGGTACTTT-3' and 5'-GAC GCCAACATAGACCACCT-3' and the length of the product was $188 \mathrm{bp}$.

The CXCR4 expression plasmid (CXCR4 NM_001008540) was purchased from Shanghai GenePharma Co., Ltd. The Wnt pathway activator (WAY 262611) was purchased from Abcam (Shanghai, China).

SW620 human colon cancer cells were provided by the Zhejiang Provincial Key Laboratory of Gastroenterology (Zhejiang, China). The instruments and equipment employed were provided by the Zhejiang Key Laboratory of Biotherapy (Zhejiang, China).

Cell cultures and transfection. SW620 human colon cancer cells were routinely cultivated in RPMI-1640 medium containing $10 \% \mathrm{FBS}$, at $37^{\circ} \mathrm{C}$ with $5 \% \mathrm{CO}_{2}$. The cells were passaged at $80 \%$ confluency, using $1 \mathrm{mmol} / \mathrm{l}$ EDTA with $0.025 \%$ trypsin for 3-5 min, and then sub-cultured at a ratio of 1:3-1:5. Cells at the logarithmic growth phase were collected for experiments. Once the cell density had increased to $30-50 \%$, Lipofectamine $^{\mathrm{TM}} 2000$ liposome transfection kit (Invitrogen Life Technologies, Carlsbad, CA, USA) was used to transfect the plasmid into the cells according to the manufacturer's instructions. Following cultivation for 2 days, the original culture medium was discarded and screened using RPMI-1640 culture medium.

MTS assay. SW620 cells in the logarithmic growth phase were collected and the cell concentration was adjusted to $5 \times 10^{4} / \mathrm{ml}$. Subsequently, $200 \mu \mathrm{l}$ of the abovementioned cell suspension was added into each well of several 96-well plates. When the cells adhered to the wall, curcumin (5-40 $\mu \mathrm{mol} / \mathrm{l})$ was added to the cells and these were cultured for $24 \mathrm{~h}$. Five parallel walls were established for each drug concentration. The supernatant was aspirated and $100 \mu$ l MTS was added into each well. A multi-mode microplate reader (Infinite M200; Tecan, Geneva, Switzerland) was used to determine the absorbance, with a detection wavelength of $490 \mathrm{~nm}$. The experiments were repeated 3 times. The cell viability was calculated using the formula: viability $(\%)=[$ (treate d-blank)/(control-blank)] x $100 \%$. The experiments were performed in triplicate.

Western blot analysis. For biochemical analysis, the cells were washed with ice-cold phosphate-buffered saline (PBS; Beyotime Institute of Biotechnology, Jiangsu, China) and lysed in radioimmunoprecipitation assay lysis buffer $[50 \mathrm{mM}$ Tris, pH 7.4; $150 \mathrm{mM} \mathrm{NaCl} ; 1 \%$ Triton X-100; $1 \%$ sodium deoxycholate; $0.1 \%$ sodium dodecyl sulfate (SDS); Beyotime Institute of Biotechnology)]. The lysates were kept on ice for $30 \mathrm{~min}$, followed by centrifugation at $12,000 \mathrm{xg}$ for $25 \mathrm{~min}$ at $4^{\circ} \mathrm{C}$. 
The clear lysate was then collected and $\beta$-catenin, axin, TCF4, E-cadherin, vimentin, NKD2, CXCR4 and $\beta$-actin proteins were separated by $12 \%$ SDS-polyacrylamide gel electrophoresis (30-50 $\mu \mathrm{g}$ protein/lane) and transferred to a polyvinylidine fluoride membrane (Beyotime Institute of Biotechnology). The membranes were incubated in $5 \%$ milk for $1.5 \mathrm{~h}$, and then with $\beta$-catenin (1:1000), axin (1:1000), TCF4 (1:2000), E-cadherin (1:2000), vimentin (1:1000), NKD2 (1:1000), CXCR4 (1:1500) and $\beta$-actin (1:2000) antibodies diluted in non-fat milk overnight. The membranes were then washed with Tris-buffered saline with Tween-20 (Beyotime Institute of Biotechnology) and incubated with the HRP-conjugated secondary antibodies for $2 \mathrm{~h}$. Immunoreactive proteins were visualized using a BeyoECL Plus kit (Beyotime Institute of Biotechnology).

Reverse transcription- $q P C R(R T-q P C R)$ analysis. The cells were washed with ice-cold PBS and total RNA was extracted from the SW620 human colon cancer cells using TRIzol reagent (Invitrogen-Technologies, Carlsbad, CA, USA) and quantified by UV spectrophotometer (Lengguang, Shanghai, China). In addition, the purity and RNA concentration were measured by the UV spectrophotometer. cDNA was obtained by reverse transcription. The PCR conditions were: $10 \mathrm{~min}$ at $25^{\circ} \mathrm{C}, 2 \mathrm{~h}$ at $37^{\circ} \mathrm{C}, 5 \mathrm{~min}$ at $85^{\circ} \mathrm{C}$ and maintained at $4^{\circ} \mathrm{C}$. cDNA was used as a template for PCR amplification of the target genes and GAPDH was used as the standard control. Amplification conditions were: Denaturation for $2 \mathrm{~min}$ at $94^{\circ} \mathrm{C}$, $30 \mathrm{sec}$ at $94^{\circ} \mathrm{C}, 30 \mathrm{sec}$ at $52^{\circ} \mathrm{C}, 5 \mathrm{sec}$ at $72^{\circ} \mathrm{C}$ and, following 40 cycles, a total extension of $4 \mathrm{~min}$ at $72^{\circ} \mathrm{C} \mathrm{(33).}$

Statistical analysis. Statistical analysis was conducted using SPSS, version 18.0 (SPSS, Inc., Chicago, IL, USA). Each experiment was performed $\geq 3$ times. Data are indicated as mean values \pm standard deviation and any differences were analyzed using a Student's t-test. $\mathrm{P}<0.05$ was considered to indicate statistically significant results.

\section{Results}

Effect of curcumin on the viability of SW620 cells. We initially investigated the effect of curcumin on the proliferation of SW620 cells. SW620 cells were treated for $24 \mathrm{~h}$ with graded concentrations of curcumin (0-40 $\mu \mathrm{mol} / \mathrm{l})$ and the cell viability was measured using an MTS assay. The results showed the cell viability s was inhibited by curcumin (Fig. 1). An increase in the concentration of curcumin led to a significant change in the rate of inhibition. The results suggested that curcumin effectively inhibited SW620 cell viability.

Curcumin inhibits Wnt signaling and expression of markers of EMT in SW620 cells. The phenotypic alterations occurring suggested that SW620 cells had undergone EMT. Thus, there were two expressions of specific EMT markers, including the epithelial marker E-cadherin and mesenchymal marker vimentin (34). Due to the conservative EMT-related signaling pathway, the $\beta$-catenin, axin, and TCF4 genes, which were associated with the Wnt signaling pathway, were selected. The $\beta$-catenin is the hub of the molecule in the Wnt signaling pathway and axin a negative regulator of the Wnt signaling

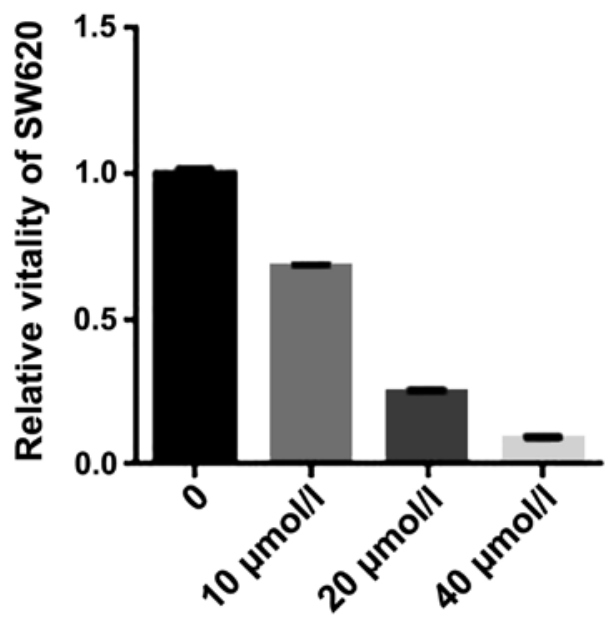

Figure 1. MTS assay for the viability of SW620 cells. Curcumin significantly suppressed the viability of SW620 cells. The viability inhibition rates of SW620 cells were treated with curcumin $(0,10,20$ and $40 \mu \mathrm{mol} / 1)$ for $24 \mathrm{~h}$. ${ }^{*} \mathrm{P}<0.01$, statistically significant.

pathway $(35,36)$. TCF4 is a Wnt pathway transcription factor and is highly expressed in colorectal cancer. To determine the effect of curcumin on the Wnt signaling pathway and EMT, we used different concentrations of curcumin to treat SW620 cells for $24 \mathrm{~h}$, and measured the protein expression using western blot analysis. We found that $\beta$-catenin, TCF4 and vimentin protein expression were significantly reduced, while the axin and E-cadherin protein expression were increased in the curcumin group (Fig. 2). By increasing the concentration of curcumin, the protein expression was more significantly altered. Thus, curcumin is capable of inhibiting the Wnt signaling pathway and EMT in SW620 cells.

Curcumin increases the expression of NKD2 and inhibits the expression of CXCR4 in SW620 cells. NKD2 acts as an inhibitor of the Wnt signaling pathway, playing an important role in tumor of EMT (37). Chemokine receptor CXCR4 acts as an $\alpha$-chemokine receptor specific for stromal-derived-factor-1. CXCR4 is highly expressed in various tumors and promotes tumor growth and metastasis (38). Therefore, to clarify whether curcumin significantly affected the genes, we carried out a biological analysis. We used different concentrations of curcumin to treat SW620 cells for $24 \mathrm{~h}$ and measured the protein expression of the genes using western blot analysis and mRNA expression RT-qPCR analysis. The NKD2 protein expression was significantly increased, while the CXCR4 protein expression was reduced in the curcumin group (Fig. 3A). The CXCR4 mRNA expression was reduced in the curcumin group (Fig. 3B) while the NKD2 mRNA expression was significantly increased in the curcumin group (Fig. 3C). Thus, curcumin increases the expression of NKD2 in the WNT signaling pathway and inhibits that of CXCR4 in the SW620 cells.

NKD2 siRNA transfection and Wnt pathway activator promotes the Wnt signaling pathway. We demonstrated whether the NKD2 siRNA and Wnt pathway activator affects the Wnt signaling pathway. SW620 cells were transfected with NKD2 siRNA for $48 \mathrm{~h}$ and the Wnt pathway activator for $24 \mathrm{~h}$, 
$\begin{array}{llll}0 & 10 & 20 & 40 \mu \mathrm{mol} / \mathrm{l}\end{array}$

$\beta$-catenin

Axin $\mathrm{m}=$

TCF4

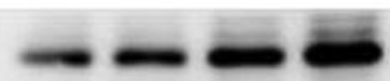



$\beta$-actin

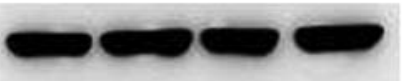

\section{$\begin{array}{llll}0 & 10 & 20 & 40\end{array} \mathbf{\mu m o l} / \mathrm{l}$}

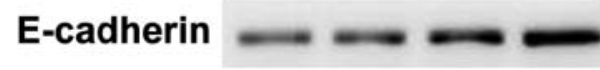

Vimentin

$\beta$-actin

Figure 2. Western blot analysis of the protein expression of $\beta$-catenin, axin, TCF4, E-cadherin and vimentin in SW620 cells following curcumin treatment for $24 \mathrm{~h}$. The concentrations of curcumin were $0,10,20$ and $40 \mu \mathrm{mol} / 1$.

A



B



Figure 3. (A) Western blot analysis of the protein expression of naked cuticle homolog 2 (NKD2) and chemokine receptor 4 (CXCR4) in SW620 cells after curcumin treatment for $24 \mathrm{~h}$. "P<0.05, statistically significant. (B and C) Real-time qPCR analysis of the mRNA expression of the CXCR4 and NKD2 in SW620 cells after curcumin treatment for $24 \mathrm{~h},{ }^{*} \mathrm{P}<0.01$, statistically significant. The concentrations of curcumin used were $0,10,20$ and $40 \mu \mathrm{mol} / 1$.

respectively, and the Wnt signaling pathway protein expression levels were detected. Western blot analysis (Fig. 4A-B) revealed that the protein expression of $\beta$-catenin and TCF4 was significantly upregulated in the NKD2 siRNA and Wnt pathway activator group compared to the control group. The results suggested that NKD2 siRNA can promote the Wnt signaling pathway by silencing the $N K D 2$ gene.
NKD2 siRNA transfection reverses curcumin inhibition of the Wnt signaling pathway and EMT in the SW620 cells. Curcumin has been previously found to inhibit Wnt signaling pathways and EMT in 95D cells (39). Therefore, we examined whether curcumin inhibit this pathway by influencing the expression of NKD2. Initially, we transfected the SW620 cells for $48 \mathrm{~h}$ with NKD2 siRNA and then treated the cells 
A

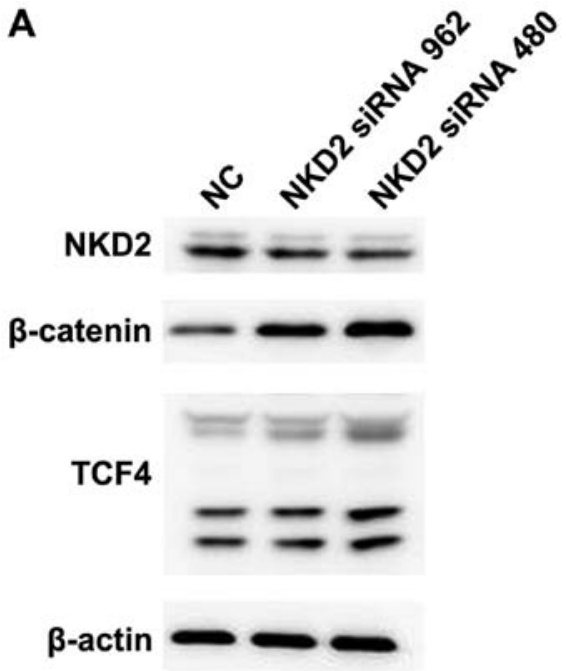

B

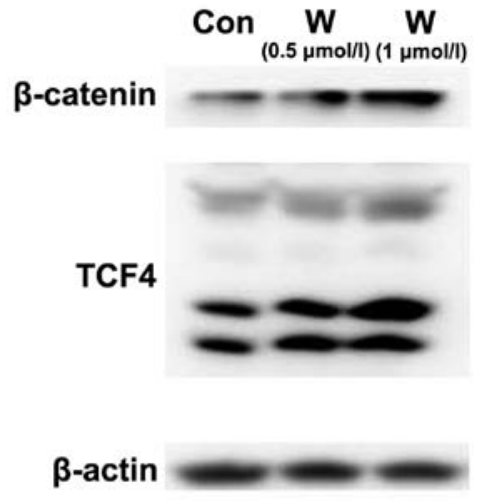

Figure 4. (A) Western blot analysis of the protein expression of naked cuticle homolog 2 (NKD2), $\beta$-catenin and TCF4 in SW620 cells after NKD2 siRNA transfection for $48 \mathrm{~h}$. NC, negative control group; NKD2 siRNA 962 group; NKD2 siRNA 480 group. (B) The protein expression of NKD2, $\beta$-catenin and TCF4 in SW620 cells treated with the Wnt pathway activator (WAY 262611) for $48 \mathrm{~h}$ by western blot analysis. Con, control group; W (0.5 $\mu$ mol/1), WAY 262611 (0.5 $\mu \mathrm{mol} / \mathrm{l})$ group; W $(1 \mu \mathrm{mol} / 1)$, WAY $262611(1 \mu \mathrm{mol} / 1)$ group.

A



B

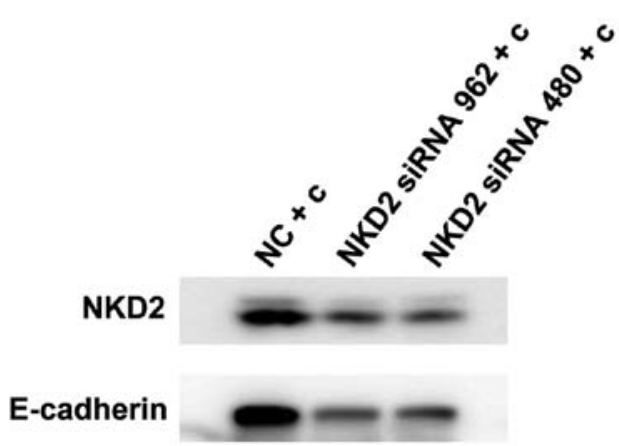

Vimentin

$\beta$-actin

Figure 5. (A) Western blot analysis of the protein expression of naked cuticle homolog 2 (NKD2), $\beta$-catenin and TCF4 in SW620 cells after NKD2 siRNA transfection for $48 \mathrm{~h}$ and curcumin treatment for $24 \mathrm{~h}$. (B) Western blot analysis of the protein expression of NKD2, E-cadherin and vimentin in SW620 cells after curcumin treatment for $24 \mathrm{~h}$ and NKD2 siRNA transfection for $48 \mathrm{~h}$. NC $+\mathrm{c}$, negative control + curcumin group; NKD2 siRNA $962+\mathrm{c}$, NKD2 siRNA 962 + curcumin group; NKD2 siRNA 480 + c, NKD2 siRNA 480 + curcumin group.

with curcumin $(10 \mu \mathrm{mol} / \mathrm{l})$ for $24 \mathrm{~h} . \beta$-catenin and TCF4 protein expression was significantly increased (Fig. 5A). The E-cadherin protein expression was reduced while the vimentin protein expression was increased in the NKD2 siRNA transfection group (Fig. 5B). Thus, previous results (39) together with those of the present study demonstrated that curcumin inhibits the Wnt signaling pathway and EMT by increasing the expression of NKD2.

NKD2 siRNA transfection increases the expression of CXCR4 in the SW620 curcumin-treated cells. CXCR4 is closely associated with EMT and the two induce and promote each other. To confirm whether curcumin inhibited the expression of CXCR4 by influencing the expression of NDK2, we transfected NKD2 siRNA for $48 \mathrm{~h}$, followed by treatment with curcumin $(10 \mu \mathrm{mol} / \mathrm{l})$ for $24 \mathrm{~h}$ in SW620 cells. We measured the protein expression using western blot analysis and the mRNA expression by RT-qPCR analysis. The CXCR4 protein expression was significantly increased in the NKD2 siRNA transfection group (Fig. 6A). The CXCR4 mRNA expression was increased in the NKD2 siRNA transfection group (Fig. 6B). Thus, our results demonstrated that curcumin inhibited the expression of CXCR4 by increasing the expression of NDK2 in the SW620 cells. 

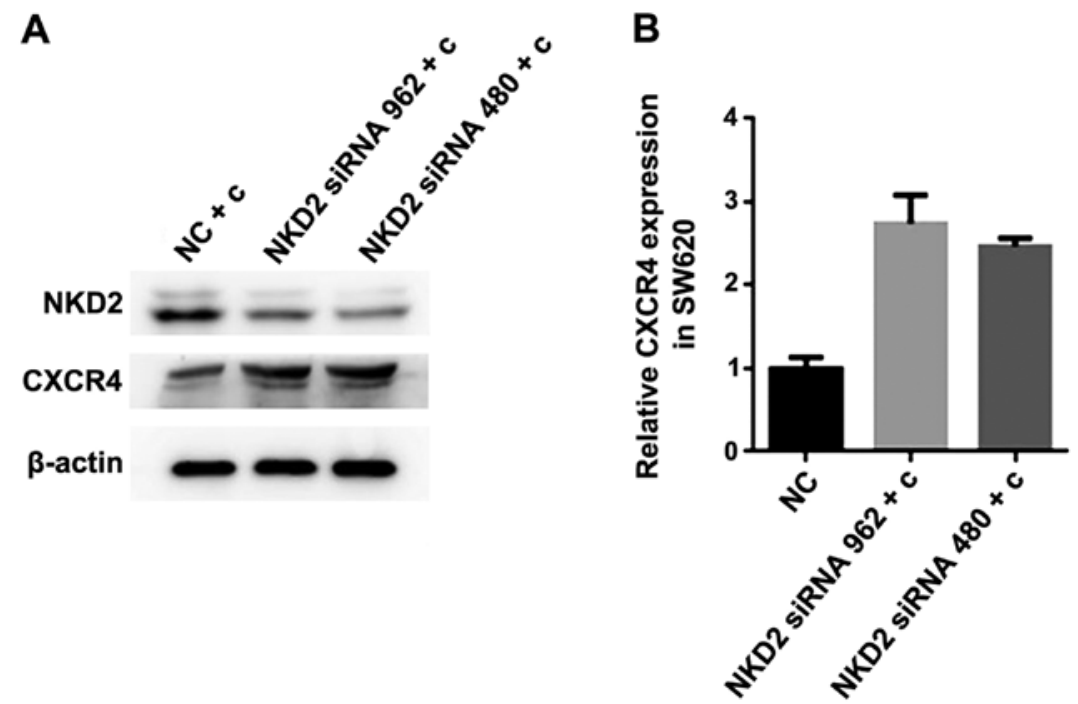

Figure 6. (A) Western blot analysis of the protein expression of naked cuticle homolog 2 (NKD2) and chemokine receptor 4 (CXCR4) in SW620 cells after NKD2 siRNA transfection for $48 \mathrm{~h}$ and curcumin treatment for $24 \mathrm{~h}$. "P<0.05, statistically significant. (B) RT-qPCR analysis of the mRNA expression of CXCR4 in SW620 cells after curcumin treatment for $24 \mathrm{~h}$ and NKD2 siRNA transfection for $48 \mathrm{~h},{ }^{*} \mathrm{P}<0.01$ was considered statistically significant. NC $+\mathrm{c}$, negative control + curcumin group; NKD2 siRNA 962 + c, NKD2 siRNA 962 + curcumin group; NKD2 siRNA 480 + c, NKD2 siRNA 480 + curcumin group.

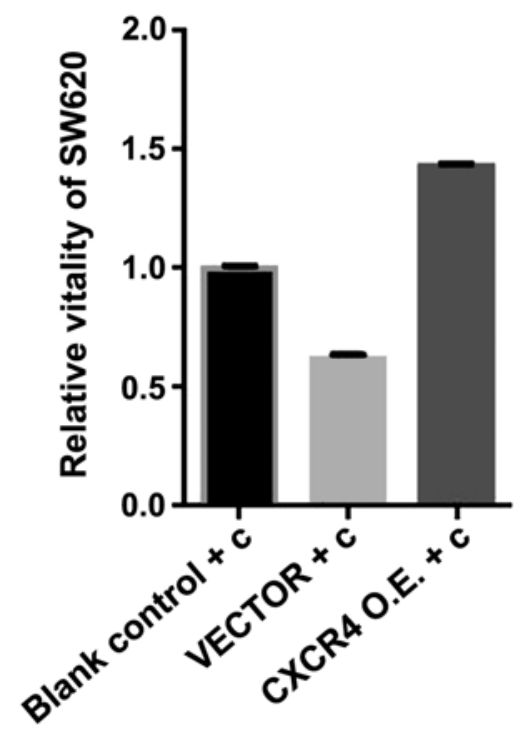

Figure 7. MTS assay for SW620 cell viability. Chemokine receptor 4 (CXCR4) expression plasmid is capable of reversing curcumin inhibition of SW620 cell viability. Blank control + c, blank control + curcumin group; vector $+\mathrm{c}$, negative control + curcumin group; CXCR4 O.E+c, CXCR4 expression plasmid+ curcumin group. ${ }^{*} \mathrm{P}<0.05$, statistically significant.

CXCR4 expression plasmid transfection increases the viability of SW620 curcumin-treated cells. As a chemokine receptor, CXCR4 reflects the invasion and metastasis of tumor cells directly. Therefore, we investigated whether CXCR4 expression plasmid affected the viability of SW620 cells treated with curcumin in vitro. We transfected CXCR4 expression plasmid for $72 \mathrm{~h}$, followed by treatment with the SW620 cells for $24 \mathrm{~h}$ with curcumin $(10 \mu \mathrm{mol} / \mathrm{l})$. Cell viability was measured using an MTS assay. As shown in Fig. 7, cell viability was increased by CXCR4 expression plasmid. The results suggested that CXCR4 expression plasmid effectively increased cell viability.
Thus, curcumin inhibits the viability of SW620 in vitro by reducing CXCR4 gene expression.

CXCR4 expression plasmid transfection reverses curcumin inhibition of EMT and promotes the expression of CXCR4 in the SW620 cells. In the process of tumor invasion and metastasis, CXCR4 is highly expressed in metastatic tissues, and tumor invasion and metastasis are closely associatied with EMT. Previous experiments (40) confirmed that curcumin is capable of inhibiting EMT in HCT116 cells. Thus, we transfected CXCR4 expression plasmid to observe whether it is able to reverse curcumin inhibition of EMT. We transfected CXCR4 expression plasmid for $72 \mathrm{~h}$ in SW620 cells, followed by treatment with curcumin $(10 \mu \mathrm{mol} / 1)$ for $24 \mathrm{~h}$. We measured the protein expression of EMT and CXCR4 expression using western blot analysis and RT-qPCR analysis. E-cadherin protein expression was reduced while the protein expression of vimentin and CXCR4 was increased in the CXCR4 expression plasmid transfection group (Fig. 8A). The CXCR4 mRNA expression was significantly increased in the CXCR4 expression plasmid transfection group (Fig. 8B). Thus, CXCR4 expression plasmid is capable of inducing EMT and promote the expression of CXCR4 in SW620 cells.

\section{Discussion}

Colon cancer, the second most frequent cancer, is a common gastrointestinal malignancy that occurs in the junction of the rectum and sigmoid colon. The highest incidence of colon cancer occurs in middle-aged and elderly individuals (41). Patients with advanced colon cancer are prone to distant metastases, particularly in the liver, lungs, and peritoneal metastasis(40). The present study indicate that EMT plays a key role in tumor metastasis . EMT refers to epithelial cells that acquire mesenchymal, fibroblast-like phenotypes with reduced cell-to-cell adhesion, and loss of cell polarity, with 

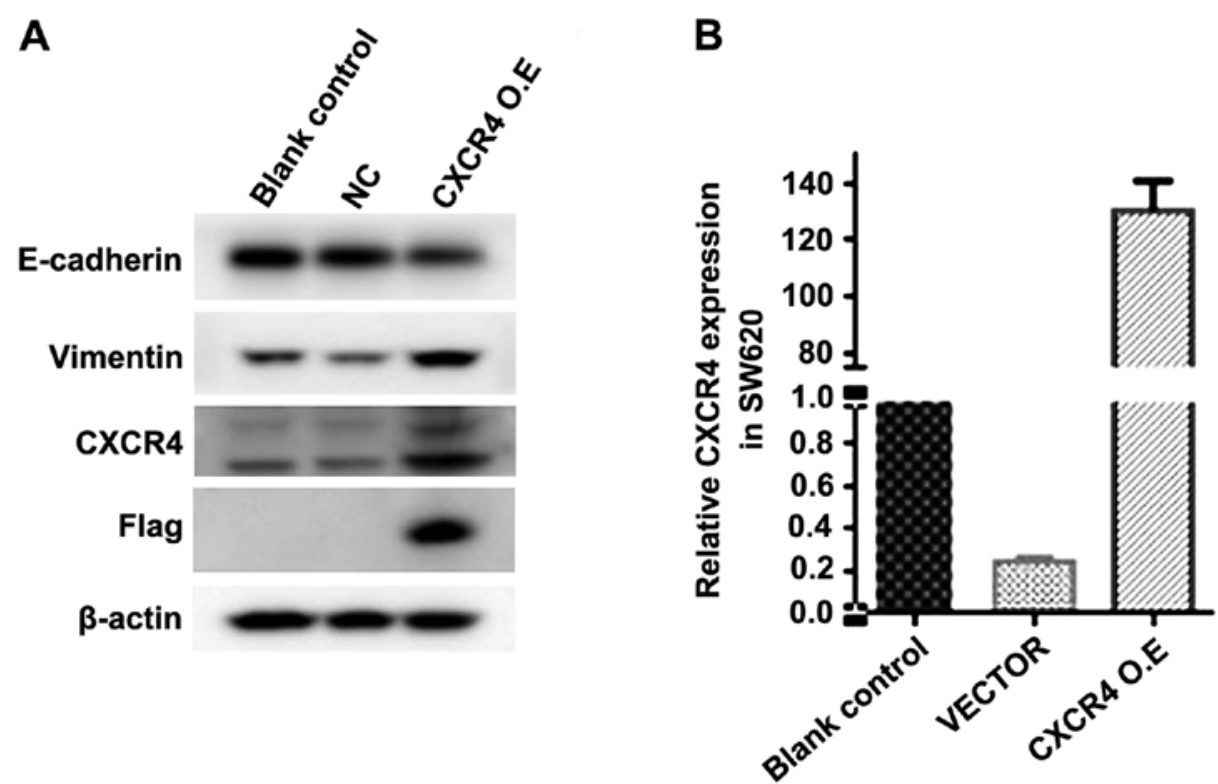

Figure 8. (A) Western blot analysis of the protein expression of E-cadherin, vimentin and chemokine receptor 4 (CXCR4) after transfection with CXCR4 expression plasmid for $72 \mathrm{~h}$ and treatment with curcumin $(10 \mu \mathrm{mol} / 1)$ for $24 \mathrm{~h}$ in SW620 cells. "P<0.05, statistically significant. (B) Real-time qPCR analysis of the mRNA expression of CXCR4 in SW620 cells after transfected CXCR4 expression plasmid for $72 \mathrm{~h}$ and then treated with curcumin (10 $\mu \mathrm{mol} / \mathrm{l})$ for $24 \mathrm{~h}$ in SW620 cells. " $\mathrm{P}<0.01$, statistically significant. Blank control + c, blank control + curcumin group ; vector + c, negative control + curcumin group; CXCR4 O.E+c, CXCR4 expression plasmid+ curcumin group.

increased migration and invasiveness (42). Furthermore, the Wnt signaling pathway, one of the important pathways in EMT, is important in embryogenesis and human diseases including various types of cancer. Wnt signals can be transduced to the canonical Wnt pathway for cell-fate determination or to the non-canonical Wnt pathway for the regulation of tissue polarity and cell movement (43). In a previous study, Deng et al reported that celecoxib inhibited the Wnt signaling pathway in colon cancer (44).

Curcumin is an antioxidant polyphenol derived from several curcuma species, commonly known as turmeric (Curcuma longa), which has been shown to inhibit carcinogen activation and angiogenesis, modulate cell survival and apoptosis, with anti-invasive and anti-metastatic effects on lung, breast and prostate cancer $(45,46)$. Curcumin induces anti-migratory activity, which functions via the Wnt signaling pathway $(28,47)$. In the current study, different concentrations of curcumin were used for $24 \mathrm{~h}$ in SW620 cells. We found that curcumin has a strong inhibitory effect on the Wnt signaling pathway and EMT. However, these anti-metastatic effects remain to be elucidated. Nevertheless, to the best of our knowledge, the present is the first study to identify that curcumin upregulates the expression of NKD2. NKD2, a secreted-type Wnt signaling inhibitor (48), suppressed the Wnt signaling pathway significantly. $\mathrm{Hu}$ et al reported that myristoylated NKD2 antagonizes the Wnt pathway by degrading dishevelled-1 at the plasma membrane (49).Therefore, it can activate the Wnt signaling pathway following transfection of NKD2 siRNA into SW620 cells. We found curcumin inhibited the Wnt pathway and EMT by increasing the expression of NKD2.

The chemokine superfamily plays multifaceted roles in the regulation of tumor development and progression. Chemokines induce leukocyte infiltration to tumors and regulate immune functions, direct the homing of tumor cells to specific metastatic sites, and regulate antigenicity at the tumor milieu (50). Thus, CXCR4 was considered an important factor in tumor cell metastasis and is a potential therapeutic target for the treatment of cancer. Recent findings have indicated that CXCR4 expression is closely associated with the Wnt signaling pathway $(51,52)$. Hu et al identified that CXCR4 promoted CRC progression and EMT was regulated by the $\mathrm{Wnt} / \beta$-catenin signaling pathway in colorectal cancer (33). Additionally, Wang et al identified that CXCR4 is crucial in the metastasis of human ovarian cancer possibly by modulating the $\mathrm{Wnt} / \beta$-catenin pathway (53). To the best of our knowledge, this is the first study to demonstrate that the anti-metastatic effects of curcumin are associated with NKD2, the Wnt signaling pathway and CXCR4 in colon cancer cells. Curcumin can also inhibit the Wnt signaling pathway through the upregulation of $N K D 2$ gene expression, suppression of EMT and the expression of CXCR4, and inhibition of tumor invasion and metastasis. Results of the present study therefore offer a new perspective on the role of curcumin in preventing the progression of cancer.

\section{Acknowledgements}

The present study was supported by a grant from the State Key Laboratory of Molecular Oncology, the Chinese Academic of Medical Sciences, Cancer Institute (Beijing, China). We would like to thank the Laboratory of Cancer Epigenetics, Biomedical Research Center, Sir Runrun Shaw Hospital, School of Medicine, Zhejiang University (Hangzhou, China) and Zhejiang Provincial Key Laboratory of Gastroenterology (Zhejiang, China) for providing the experimental facilities, instruments and guidance. 


\section{References}

1. Noreen F, Röösli M, Gaj P, Pietrzak J, Weis S, Urfer P, Regula J, Schär P and Truninger K: Modulation of age- and cancer-associated DNA methylation change in the healthy colon by aspirin and lifestyle. J Natl Cancer Inst 106: 106, 2014.

2. Pelser C, Arem H, Pfeiffer RM, Elena JW, Alfano CM, Hollenbeck AR and Park Y: Prediagnostic lifestyle factors and survival after colon and rectal cancer diagnosis in the National Institutes of Health (NIH)-AARP Diet and Health Study. Cancer 120: 1540-1547, 2014.

3. Winkels RM, Heine-Bröring RC, van Zutphen M, van HartenGerritsen S, Kok DE, van Duijnhoven FJ and Kampman E: The COLON study: Colorectal cancer: Longitudinal, Observational study on Nutritional and lifestyle factors that may influence colorectal tumour recurrence, survival and quality of life. BMC Cancer 14: 374, 2014

4. Sunkara V and Hébert JR: The colorectal cancer mortality-toincidence ratio as an indicator of global cancer screening and care. Cancer 121: 1563-1569, 2015.

5. Huang W, Liu Z, Zhou G, Tian A and Sun N: Magnetic gold nanoparticle-mediated small interference RNA silencing Bag-1 gene for colon cancer therapy. Oncol Rep 35: 978-984, 2016.

6. Heerboth S, Housman G, Leary M, Longacre M, Byler S, Lapinska K, Willbanks A and Sarkar S: EMT and tumor metastasis. Clin Transl Med 4: 6, 2015.

7. Kabashima A, Higuchi H, Takaishi H, Matsuzaki Y, Suzuki S, Izumiya M, Iizuka H, Sakai G, Hozawa S, Azuma T, et al: Side population of pancreatic cancer cells predominates in TGF-beta-mediated epithelial to mesenchymal transition and invasion. Int J Cancer 124: 2771-2779, 2009.

8. Tsuji T, Ibaragi S and Hu GF: Epithelial-mesenchymal transition and cell cooperativity in metastasis. Cancer Res 69: 7135-7139, 2009.

9. Hay ED: The mesenchymal cell, its role in the embryo, and the remarkable signaling mechanisms that create it. Dev Dyn 233: 706-720, 2005.

10. Ombrato L and Malanchi I: The EMT universe: Space between cancer cell dissemination and metastasis initiation. Crit Rev Oncog 19: 349-361, 2014.

11. Zheng H and Kang Y: Multilayer control of the EMT master regulators. Oncogene 33: 1755-1763, 2014.

12. Guarino M: Epithelial-mesenchymal transition and tumour invasion. Int J Biochem Cell Biol 39: 2153-2160, 2007.

13. Natalwala A, Spychal R and Tselepis C: Epithelial-mesenchymal transition mediated tumourigenesis in the gastrointestinal tract. World J Gastroenterol 14: 3792-3797, 2008.

14. Wang Y and Zhou BP: Epithelial-mesenchymal Transition-A Hallmark of Breast Cancer Metastasis. Cancer Hallm 1: 38-49, 2013.

15. Gonzalez EJ, Arms L and Vizzard MA: The role(s) of cytokines/chemokines in urinary bladder inflammation and dysfunction. BioMed Res Int 2014: 120525, 2014.

16. Sallusto $\mathrm{F}$ and Baggiolini M: Chemokines and leukocyte traffic. Nat Immunol 9: 949-952, 2008.

17. Hu XM, Liu YN, Zhang HL, Cao SB, Zhang T, Chen LP and Shen W: CXCL12/CXCR4 chemokine signaling in spinal glia induces pain hypersensitivity through MAPKs-mediated neuroinflammation in bone cancer rats. J Neurochem 132: 452-463, 2015.

18. Batsi O, Giannopoulou I, Nesseris I, Valavanis C, Gakiopoulou H, Patsouris ES, Arapandoni-Dadioti $\mathrm{P}$ and Lazaris $\mathrm{AC}$ : Immunohistochemical evaluation of CXCL12-CXCR4 axis and VEGFR3 expression in primary urothelial cancer and its recurrence. Anticancer Res 34: 3537-3542, 2014

19. Cojoc M, Peitzsch C, Trautmann F, Polishchuk L, Telegeev GD and Dubrovska A: Emerging targets in cancer management: Role of the CXCL12/CXCR4 axis. Onco Targets Ther 6: 1347-1361, 2013.

20. Zhang Z, Ni C, Chen W, Wu P, Wang Z, Yin J, Huang J and Qiu F: Expression of CXCR4 and breast cancer prognosis: A systematic review and meta-analysis. BMC Cancer 14: 49, 2014.

21. Sahebkar A: Dual effect of curcumin in preventing atherosclerosis: The potential role of pro-oxidant-antioxidant mechanisms. Nat Prod Res 29: 491-492, 2015.

22. Maheshwari RK, Singh AK, Gaddipati J and Srimal RC: Multiple biological activities of curcumin: A short review. Life Sci 78: 2081-2087, 2006.
23. Zhang X, Chen Q, Wang Y, Peng W and Cai H: Effects of curcumin on ion channels and transporters. Front Physiol 5: 94 , 2014.

24. Jiang GM, Xie WY, Wang HS, Du J, Wu BP, Xu W, Liu HF, Xiao P, Liu ZG, Li HY, Liu SQ, Yin WJ, Zhang QG, Liang JP and Huang HJ: Curcumin combined with FAPalphac vaccine elicits effective antitumor response by targeting indolamine2,3-dioxygenase and inhibiting EMT induced by TNF-alpha in melanoma. Oncotarget 6: 25932-25942, 2015.

25. Sherwood V: WNT signaling: An emerging mediator of cancer cell metabolism? Mol Cell Biol 35: 2-10, 2015.

26. Tan CW, Gardiner BS, Hirokawa Y, Smith DW and Burgess AW: Analysis of Wnt signaling $\beta$-catenin spatial dynamics in HEK293T cells. BMC Syst Biol 8: 44, 2014

27. Chen J, Xu L, Hu X, Zhang J, Xu C, Li G and Jiang H Curcumin regulates VSMC phenotype transition via modulation of Notch and Wnt signaling pathways. Drug Dev Res 74: 252-258, 2013

28. Kim HJ, Park SY, Park OJ and Kim YM: Curcumin suppresses migration and proliferation of Hep3B hepatocarcinoma cells through inhibition of the Wnt signaling pathway. Mol Med Rep 8: 282-286, 2013

29. Van Raay TJ, Coffey RJ and Solnica-Krezel L: Zebrafish Naked1 and Naked2 antagonize both canonical and non-canonical Wnt signaling. Dev Biol 309: 151-168, 2007.

30. Shi YJ and Huo K: Nkd2, a negative regulator of Wnt pathway, delays mitotic exit in Hela cell. Genes Genomics 35: 569-573, 2013.

31. Kunnumakkara AB, Diagaradjane P, Anand P, Harikumar KB, Deorukhkar A, Gelovani J, Guha S, Krishnan S and Aggarwal BB: Curcumin sensitizes human colorectal cancer to capecitabine by modulation of cyclin D1, COX-2, MMP-9, VEGF and CXCR4 expression in an orthotopic mouse model. Int J Cancer 125: 2187-2197, 2009.

32. Skommer J, Wlodkowic D and Pelkonen J: Gene-expression profiling during curcumin-induced apoptosis reveals downregulation of CXCR4. Exp Hematol 35: 84-95, 2007.

33. Hu TH, Yao Y, Yu S, Han LL, Wang WJ, Guo H, Tian T, Ruan ZP, Kang XM, Wang J, et al: SDF-1/CXCR4 promotes epithelial-mesenchymal transition and progression of colorectal cancer by activation of the $\mathrm{Wnt} / \beta$-catenin signaling pathway. Cancer Lett 354: 417-426, 2014.

34. Chaw SY, Majeed AA, Dalley AJ, Chan A, Stein S and Farah CS: Epithelial to mesenchymal transition (EMT) biomarkers-E-cadherin, beta-catenin, APC and Vimentin-in oral squamous cell carcinogenesis and transformation. Oral Oncol 48: 997-1006, 2012.

35. Tacchelly-Benites O, Wang Z, Yang E, Lee E and Ahmed Y: Toggling a conformational switch in Wnt/ $\beta$-catenin signaling: Regulation of Axin phosphorylation. The phosphorylation state of Axin controls its scaffold function in two Wnt pathway protein complexes. Bioessays 35: 1063-1070, 2013.

36. Gupta A, Verma A, Mishra AK, Wadhwa G, Sharma SK and Jain CK: The Wnt pathway: Emerging anticancer strategies. Recent Pat Endocr Metab Immune Drug Discov 7: 138-147, 2013.

37. Dong Y, Cao B, Zhang M, Han W, Herman JG, Fuks F, Zhao Y and Guo M: Epigenetic silencing of NKD2, a major component of Wnt signaling, promotes breast cancer growth. Oncotarget 6: 22126-22138, 2015.

38. Xu C, Zhao H, Chen $\mathrm{H}$ and Yao Q: CXCR4 in breast cancer: Oncogenic role and therapeutic targeting. Drug Des Devel Ther 9: 4953-4964, 2015

39. Xu JH, Yang HP, Zhou XD, Wang HJ, Gong L and Tang CL: Role of wnt inhibitory factor-1 in inhibition of bisdemethoxycurcumin mediated Epithelial-to-Mesenchymal transition in highly metastatic lung cancer 95D cells. Chin Med J (Engl) 128: 1376-1383, 2015.

40. Buhrmann C, Kraehe P, Lueders C, Shayan P, Goel A and Shakibaei M: Curcumin suppresses crosstalk between colon cancer stem cells and stromal fibroblasts in the tumor microenvironment: potential role of EMT. PLoS One 9: e107514, 2014.

41. Braendegaard WS, Baatrup G, Pfeiffer P and Qvortrup C: Trends in colorectal cancer in the elderly in Denmark, 1980-2012. Acta Oncol 55 Suppl 1: 29-39, 2016.

42. Tiwari N, Gheldof A, Tatari M and Christofori G: EMT as the ultimate survival mechanism of cancer cells. Semin Cancer Biol 22: 194-207, 2012.

43. Hu T and Li C: Convergence between Wnt- $\beta$-catenin and EGFR signaling in cancer. Mol Cancer 9: 236, 2010. 
44. Deng Y, Su Q, Mo J, Fu X, Zhang Y and Lin EH: Celecoxib downregulates CD133 expression through inhibition of the Wnt signaling pathway in colon cancer cells. Cancer Invest 31: 97-102, 2013

45. Jagtap S, Meganathan K, Wagh V, Winkler J, Hescheler J and Sachinidis A: Chemoprotective mechanism of the natural compounds, epigallocatechin-3-O-gallate, quercetin and curcumin against cancer and cardiovascular diseases. Curr Med Chem 16: 1451-1462, 2009.

46. Chen QY, Jiao DM, Wang LF, Wang L, Hu HZ, Song J, Yan J, Wu LJ and Shi JG: Curcumin inhibits proliferation-migration of NSCLC by steering crosstalk between a Wnt signaling pathway and an adherens junction via EGR-1. Mol Biosyst 11: 859-868, 2015.

47. Leow PC, Bahety P, Boon CP, Lee CY, Tan KL, Yang T and Ee PL: Functionalized curcumin analogs as potent modulators of the Wnt/ $\beta$-catenin signaling pathway. Eur J Med Chem 71: 67-80, 2014.

48. Katoh M and Katoh M: WNT signaling pathway and stem cell signaling network. Clin Cancer Res 13: 4042-4045, 2007.
49. Hu T, Li C, Cao Z, Van Raay TJ, Smith JG, Willert K, Solnica-Krezel L and Coffey RJ: Myristoylated Naked2 antagonizes Wnt-beta-catenin activity by degrading Dishevelled-1 at the plasma membrane. J Biol Chem 285: 13561-13568, 2010.

50. Ben-Baruch A: The multifaceted roles of chemokines in malignancy. Cancer Metastasis Rev 25: 357-371, 2006.

51. Choe $Y$ and Pleasure SJ: Wnt signaling regulates intermediate precursor production in the postnatal dentate gyrus by regulating CXCR4 expression. Dev Neurosci 34: 502-514, 2012.

52. Zhao S, Wang J and Qin C: Blockade of CXCL12/CXCR4 signaling inhibits intrahepatic cholangiocarcinoma progression and metastasis via inactivation of canonical Wnt pathway. J Exp Clin Cancer Res 33: 103, 2014.

53. Wang J, Cai J, Han F, Yang C, Tong Q, Cao T, Wu L and Wang Z: Silencing of CXCR4 blocks progression of ovarian cancer and depresses canonical Wnt signaling pathway. Int J Gynecol Cancer 21: 981-987, 2011. 